\title{
PRECISION OF COLOR TEMPERATURE MEASUREMENTS UNDER VARIOUS OBSERVING CONDITIONS; A NEW COLOR COMPARATOR FOR INCANDESCENT LAMPS
}

\author{
By Deane B. Judd
}

\section{ABSTRACT}

It is important in many kinds of scientific and technical research to know the color temperature of a source of light because for many common light sources it is possible to deduce from the value of color temperature the relative amounts of energy being emitted throughout the whole spectrum. Instead of measuring these relative spectral energies radiometrically for each incandescent lamp submitted for standardization, it is therefore customary to compare the test lamp as to color with a standard lamp previously tested radiometrically; that is, the color temperature of the test lamp is determined by comparison with a standard lamp. This comparison has been carried out at the National Bureau of Standards by means of either the $3^{\circ}$ circular field of the rotatory dispersion colorimeter or the $6^{\circ}$ circular field of the Martens photometer. Preliminary to the construction of a color comparator which was to be designed to permit color temperature determinations with a maximum of precision an investigation was made of the effect on precision of various observing conditions. The conditions investigated included field size, width of dividing line, and convenience of the brightness adjustment. It was found that the simple apparatus used for these preliminary tests could be made to yield color temperature determinations of more than double the precision previously obtainable by visual comparison at the Bureau of Standards.

I. Introduction

II. Apparatus _................ 1162

III. Method of procedure

IV. Experimental results and interpretation

1. Sensibility as a function of field size

2. Sensibility as a function of width of the dividing line $\ldots \ldots \ldots 1171$

3. Importance of the substitution method $\ldots \ldots \ldots 117$

4. Comparison with the precision obtained by use of other apparatus

V. Summary apparatus

\section{INTRODUCTION}

It has been found by experiment that the relative energy distribution from many common incandescent light sources is, in the visible spectrum, practically identical with that from a Planckian radiator, though the true temperature of the incandescent filament is not generally the temperature of the Planckian radiator giving the most nearly identical energy distribution. For some purposes the spectral distribution of energy for such light sources may be satisfactorily specified by a single number, the "color temperature," where the color temperature of a light source is defined is "the temperature at which a Planckian radiator would emit radiant cnergy competent to croke a 
color of the same quality as that evoked by the radiant energy from the source in question." 1

Requests for the calibration of incandescent lamps in terms of color temperature are frequent. Such calibration may be accomplished by direct comparison with standard lamps in a suitable field or by a comparison in conjunction with the Davis-Gibson ${ }^{2}$ filters or by means of the rotatory dispersion colorimeter, ${ }^{3}$ the primary standard lamp having been established by radiometric means.

The purposes of the present paper are:

To give a preliminary general description of apparatus suggested by Irwin G. Priest ${ }^{4}$ for the purpose of making possible color temperature determinations of incandescent lamps with a higher degree of precision than has been possible with the rotatory dispersion colorimeter, the Martens photometer, or other color comparators commonly used for lamps. ${ }^{5}$

To present results of precision tests with the new apparatus under various observing conditions (differing field sizes, differing widths of dividing line, and light dividing line $v$. dark dividing line).

To compare the precision obtained by means of the new apparatus with that obtained by the $3^{\circ}$ circular field of the rotatory dispersion colorimeter, ${ }^{6}$ the $6^{\circ}$ circular field of the Martens photometer, ${ }^{7}$ and the $4^{\circ}$ square field of Priest's monochromatic colorimeter. ${ }^{8}$

\section{APPARATUS}

Essentially the apparatus consists of two mat surfaces of opal glass set at an angle of $60^{\circ}$ and viewed by reflected light. The surfaces are separated by a sheet of lead foil so that light falling on the one can not contribute to the brightness of the other. The line of intersection of the two surfaces is vertical and constitutes the dividing line of the photometric field. We may describe this arrangement as an opaque $60^{\circ}$ prism (about $20 \mathrm{~cm}$ high) having two mat surfaces of high reflectance, and shall refer to it simply as the prism. Each of the two illuminating beams (quite definitely diverging) strikes its prism face at an angle approximately $30^{\circ}$ from the normal. ${ }^{9}$ Since the prism is viewed directly from the front, the direction of view is about $60^{\circ}$ from the normals to both surfaces.

1 Irwin G. Priest, The Colorimetry and Photometry of Daylight and Incandescent Illuminants by the Method of Rotatory Dispersion, J. Opt. Soc. Am. and Rev. Sci. Inst., 7, p. 1180; 1923.

2 Raymond Davis and K. S. Gibson, Reproducible Liquid Filters for the Determination of the Color Temperatures of Incandescent Lamps, Phys. Rev. (2), 29, p. 916; 1927. This reference cites an abstract; the complete paper will appear as a Miscellaneous Publication of the National Bureau of Standards.

'Irwin G. Priest, Measurement of the Color Temperature of the More Efficient Artificial Light Sources by the Method of Rotatory Dispersion, B. S. Sci. Paper No. 443, 18, pp. 221-234; 1922.

The general plan and many of the details of the apparatus are due to Mr. Priest. The actual construction was carried out by R. S. Hunter and J. O. Riley with some assistance from the shop. Hunter and Riley have also collahorated with the author in the design of a few of the details.

The rotatory dispersion colorimeter has a circular photometric field of about $3^{\circ}$ diameter. The Martens photometer fleld is a $6^{\circ}$ circle. The Lummer-Brodhun contrast photometer field is elliptical and of varying size $\left(10^{\circ}\right.$ or $\left.15^{\circ}\right)$. All these instruments are monocular and involve the use of an artificial pupil. The hope for higher precision with the new apparatus was based largely on the fact that it was to provide a large fleld ( $17^{\circ}$ by $20^{\circ}$ rectangular) which could be viewed directly with both eyes.

F. F. Martens, Utber ein neues Polarisationsphotometer, Phys Zs., 1, pp. 299-303; 1900. The Martens photometer referred to herein is made by Schmidt and Haensch.

- Irwin G. Priest, Apparatus for the Determination of Color in Terms of Dominant Wave Length,

Purity and Brightness, J. Opt. Soc. Am. and Rev. Sci. Inst., 8, pp. 173-200; 1924.

the dividing line since the observing fleld is not quite uniform, but rather increases with distance from light sources the since the two outer edges of the prism are generally somewhat closer to their respective light sources than are the other portions of the half fields. Though this lack of uniformity was noticeable, it seemed to have no undesirable consequences. Most of it could be overcome, however, by making the Incident beams approximately normal to the respective prism faces instead of approximately at $30^{\circ}$ from 
The brightness of the two surfaces may be adjusted to equality by adjusting the distances of the lamps from the surfaces.

Throughout a considerable portion of the preliminary tests the prism faces were viewed directly, in which cases the tridimensionality of the field was more or less apparent (and possibly disturbing) to the observer. The two outer edges of the prism and its supports were hidden from the observer by a limiting diaphragm in the plane of the dividing line perpendicular to the line of sight. By varying the size of the opening of this diaphragm the field size could be changed at will up to a rectangle $17^{\circ}$ vertical by $20^{\circ}$ horizontal for an observing distance of $35 \mathrm{~cm}$. For the remainder of the tests the aperture of this diaphragm was covered with a translucent screen (tissue paper or a glass plate ground on one side). It is to be expected that the use of such a field would avoid the possibly disturbing effects introduced by the tridimensionality of the field when the prism is observed directly. ${ }^{10}$

For neither the prism field nor the flat field could the line of division between the two halves of the field be made to disappear; there was a dividing line of brightness perhaps 0.6 that of the field and of width about $0.5 \mathrm{~mm} .{ }^{11}$

The adjustment of brightness by movement of the lamps was facilitated by placing them on carriages. By turning a small crank held between thumb and forefinger the observer can cause one lamp to approach the prism and the other to recede. This brightness adjustment is considerably facilitated by the use of ball bearings throughout the mechanism. It has long been recognized that convenience in making the brightness adjustment is an important factor in obtaining high precision of any setting which depends on making a chromaticity (hue and saturation) match. Some observers for their best sensibility even require the brightness to be oscillated about the match point with an amplitude of 5 or 10 per cent and a period of perhaps a second. Preliminary tests indicate that the device incorporated in the new comparator for adjustment of brightness approaches in convenience, but does not equal, that of the Martens photometer.

The lamps were operated on storage-battery circuits. The voltages applied to the lamps were controlled by rheostats, a rough adjustment and a fine adjustment being provided.

The immediate surroundings of the field were not black, but rather a fairly dark gray. The room lights (screened, of course, from the prism) were kept burning during all observations. Since the distance of the observing eye (or eyes) was not controlled exactly (no head support was used) the field size specified by the angle subtended by the diameter was not constant; it may have varied at particular times from the average values given by as much as 10 per cent.

10 The use of the translucent screen restricts the application of the comparator for color-temperature determination to lamps of nearly the same candle power. It is evident that when one lamp is considerably closer to the prism than the other, as is inevitable in comparing lamps of widely different calection from the relatively greater proportion of light falling directly on the translucent scred

the prism constitutes a source of error which can not safely be neglected. 11 The two pieces of opal glass forming the prism faces were chosen from stock by reason of their relativen good approach to planeness. They warped sufficiently on being ground to a plane mat surface to pret any a good approach to coincidence of the two edges. Furthermore, the opal glass was so brittlo that an attempt to force the edges into good coincidence resulted

$15377^{\circ}-30-13$ 


\section{METHOD OF PROCEDURE}

In all settings the right half of the field was illuminated by light from a 400-watt Mazda projection lamp at a voltage of 80.0 which yielded a color temperature of about $2,700^{\circ} \mathrm{K}$. The observer's left hand rested on the rheostat knob by which the applied voltage of the comparison lamp (also a 400-watt Mazda projection lamp) illuminating the left half of the field was controlled; the right hand grasped the crank by which the relative brightness was adjusted. In general, the observer was required to make 30 settings without rest, first 10 median settings, then 10 settings of "greatest imperceptible difference" (GID), and finally 10 settings of "least perceptible difference" (LPD). Then the observer rested while some change was made in the experimental conditions. It was hoped (and this hope was reasonably well realized) that reliable information concerning the precision of settings of color temperature could be obtained from 30 such settings.

For the median settings the observer adjusted the applied voltage of the comparison lamp so that its color temperature was noticeably too high, then, as nearly as he could judge, about equally too low. After a few such trial adjustments of the rheostat, he endeavored by the kinaesthetic sense to strike the mean position. When the observer was satisfied that the setting was neither too high nor too low, the applied voltage was recorded as a median setting.

For the GID settings the observer adjusted the applied voltage of the comparison lamp so that its color temperature was noticeably too high; then he decreased the applied voltage by small steps until (perhaps, on the fifth or sixth step) the color temperatures of the lamps appeared to be equal. This voltage was recorded as a high GID setting. Then the observer made a low GID setting. Five such pairs made up the 10 GID settings.

For the LPD settings the observer adjusted the applied voltage of the comparison lamp so that its color temperature was noticeably too low; then he increased the applied voltage by small steps until, after having passed through the "match point," the color temperature of the comparison lamp appeared to be just noticeably too high. This voltage was recorded as a high LPD setting. Then the observer made a low LPD setting. Five such pairs made up the ten LPD settings.

Undoubtedly the precision of setting for a color match depends upon the physiological condition of the observer at the moment of making the observation, and the precision is usually assumed to increase if the condition be better, but we can not be sure that a sick observer would make less precise settings than a well one, nor do we know that an observer just arising from a night's sleep would make better settings than one who had been observing several hours. There seems to be a tendency for the first group of settings made to be less precise than those which follow immediately thereafter. Such a tendency has been called the "practice effect" though it is probable that adaptation of the visual mechanism to the stimulus is an important factor also. There is a further tendency for the last of a long series of groups to have a lower precision than those which precede it. Such a tendency has been called the "fatigue effect," but it may well be due to a relaxing of the observer as the end of his task approaches. 
The concepts of "practice" on the one hand and "fatigue" on the other are bound to be more or less successful as explanations, because a change in precision which the one fails to account for can be accounted for by assuming the presence of the other. Perhaps, it is nearer the truth merely to say that precision of setting for a color match is subject to irregular fluctuations (hourly, daily, monthly, and longtime) of obscure cause which are at the same time too large and too consistent to be random variations accounted for by the theory of errors. At any rate, the task of making many settings for color match of the utmost precision requires a very happy balance between tension and relaxation. The observer must maintain a steady pace that permits each setting to be the result of composed as well as concentrated effort.' Distractions and the complete exclusion of distractions alike contribute to error; the former tend toward too little concentration, the latter toward too much. Any factor which the observer believes to be important constitutes a distraction that really is important and deserves immediate attention.

Furthermore, the observer must be interested in the observations, must believe that they are important, and must have confidence in his ability to carry the observations to a conclusion without interruption and without altering his pace. Every effort was made both to reduce the amplitude of the fluctuations and to avoid vitiation of the results by such fluctuations in precision as did occur. Longtime fluctuations were avoided because the observations all were taken within four weeks (July 20 to August 14, 1929). The effect of monthly and daily fluctuation was avoided to a great extent by reason of the fact that each stimulus variable (for example, field size or width of dividing line) was investigated throughout its entire range within a single day. Hourly fluctuations (the "practise" and "fatigue" effects) were rendered unimportant both by the order adopted for the taking of settings and by taking a large number of settings.

\section{EXPERIMENTAL RESULTS AND INTERPRETATION}

Two measures of sensibility to change in color temperature have been used: (1) The probable error of a single observation computed from a group of 10 observations (labeled $P E_{\text {single }}$ ), and (2) the "just doubtful difference." 12

The probable error of a single observation was computed by means of Peter's approximation formula: ${ }^{13}$

$$
P E_{\text {slngle }}=0.8453 \frac{\Sigma|v|}{\sqrt{n(n-1)}}
$$

where $\Sigma|v|$ is the arithmetical sum of the residuals computed from

12 This measure of sensibility was introduced by Priest (Irwin G. Priest and F. G. Brickwedde, The Minimum Perceptible Colorimetric Purity as a Function of Dominant Wave Length with Sunlight as Neutral Stimulus, J. Opt. Soc. Am. and Rev. Sci. Inst., 13, p. 306; 1926), and is defined as the mean between the GID and the LPD, see below. It may be shown from the classical theory of errors that the "just doubtful difference" is a measure of sensibility less dependent on observing habits than either the "greatest imperceptible difference" or the "least perceptible difference" from which it is derived. The "just doubtful difference" has been embodied in a new unit of saturation, the "satron," introduced by Priest, see footnote $25, \mathrm{p} .1176$.

${ }_{13} \mathrm{~J}$. W. Mellor, Higher Mathematics, London, Longmans-Green, p. 516; 1905. 
the arithmetical mean, and $n$ is the number of settings. For the median settings the formula becomes $(n=10)$ :

$$
P E_{\text {single }}=0.0891 \Sigma|v|
$$

For the GID and LPD settings we compute residuals about the mean of the five high and the mean of the five low settings. The probable error of a single observation is taken as the mean of the probable errors computed for each five settings separately $(n=5)$ which results in the formula:

$$
P E_{\text {single }}=0.0945\left(\Sigma|v|_{\text {high }}+\Sigma|v|_{\text {low }}\right)
$$

(GID and LPD)

From the classical theory of errors there is reason to believe that both the GID and the LPD settings should result in greater precision than median settings. The ratio of the probable error of a GID setting to that of a median setting was predicted on the basis of the theory to fall between 0.63 and 0.76 for acceptable observing technique. The mean of 120 observations taken during the first week of the experiment (observer DBJ, field size $16^{\circ}$ or larger) gave 0.68 for this ratio. Prevoius work reported by Priest and Judd on sensibility to dominant-wave-length change (see footnote 18, p. 1170) gives 0.76 for this ratio. It was also found from similar data that the probable crror of a single LPD setting was 0.81 of the probable error of a single median setting. ${ }^{14}$ In spite of the expected slight inferiority of the median setting, which was furthermore experimentally realized by observer DBJ, it was nevertheless deemed superfluous to take this in to account because each individual value is subject to considerable uncertainty; ${ }^{15}$ the average of the probable errors by all three methods of setting was taken as a measure of the precision actually attained under the experimental conditions.

The "just doubtful difference" is labeled (GID + LPD)/2, and as the label implies is the mean of the greatest imperceptible difference (GID) and the least perceptible difference (LPD). The GID is onehalf the difference between the mean of the five high GID settings and the mean of the five low GID settings. Similarly, the LPD is onehalf the difference between the mean of the five high LPD settings and the mean of the five low LPD settings. The "just doubtful difference" (GID + LPD)/2, may in a sense be taken as a measure of the sensibility which the observer believes he is obtaining. With constant experimental technique it is reasonable to expect that the actual experimental sensibility (measured by the average $P E_{\text {single }}$ by the three methods of setting) will be proportional to the sensibility which the observer believes he is attaining (measured by the (GID + LPD)/2). See Table 2 for experimental tests of this proportionality.

11 This ratio has not been worked out theoretically.

16 The probable error of these probable errors is quite high-about 0.16 of the values, themselves. The probable error of a single $\rightarrow I D$ settiug was actually greater than the probable error of a single median setting slrteon tlmes out of the 43 groups of observations permitting this comparison. 
TABLE 1.-Summary of determinations of sensibility to change in color temperature OBSERVER, DBJ

\begin{tabular}{|c|c|c|c|c|c|c|c|}
\hline Date & $\begin{array}{c}P E_{\text {singio }} \\
\text { volts }\end{array}$ & $\underset{\text { volts }}{(\text { GID }+\mathrm{LPD}) / 2}$ & \multicolumn{3}{|c|}{ Eyes } & $\begin{array}{c}\text { Field } \\
\text { size, } \\
\text { degrees }\end{array}$ & Remarks \\
\hline July 20. & $\begin{array}{r}0.86 \\
.43 \\
.23\end{array}$ & $\begin{array}{r}3.30 \\
1.36 \\
.61\end{array}$ & & & $\begin{array}{l}\mathrm{X} \\
\mathrm{X} \\
\mathrm{X}\end{array}$ & 16 & \\
\hline July 22 & $\begin{array}{r}1.09 \\
.49 \\
.54 \\
.34\end{array}$ & $\begin{array}{l}3.84 \\
1.32 \\
1.91 \\
1.00\end{array}$ & & & $\begin{array}{l}\mathrm{X} \\
\mathrm{X} \\
\mathbf{X}\end{array}$ & $\begin{array}{l}1-\ldots \\
16_{-} \\
16- \\
16\end{array}$ & $\begin{array}{l}5 \mathrm{~mm} \text { div. black. } \\
19 \mathrm{~mm} \text { div. black. } \\
1.5 \mathrm{~mm} \text { div. black. }\end{array}$ \\
\hline July 23 & $\begin{array}{l}.46 \\
.42 \\
.28 \\
.41\end{array}$ & $\begin{array}{l}1.30 \\
1.47 \\
1.22 \\
1.18\end{array}$ & $\begin{array}{l}\mathrm{X} \\
\mathrm{X} \\
\mathrm{X} \\
\mathrm{X}\end{array}$ & & & $\begin{array}{l}6 \ldots- \\
6 \ldots- \\
6 \ldots- \\
6 \ldots\end{array}$ & $\begin{array}{l}\text { Martens, no circle. } \\
\text { Left eye bandaged. } \\
\text { Do. } \\
\text { Martens, no circle. }\end{array}$ \\
\hline July 24 & $\begin{array}{l}.26 \\
.25 \\
.28 \\
.21\end{array}$ & $\begin{array}{l}.68 \\
.66 \\
.70 \\
.82\end{array}$ & $\begin{array}{l}\mathrm{X} \\
\mathrm{X} \\
\mathrm{X} \\
\mathrm{X}\end{array}$ & & & $\begin{array}{l}16 \\
6 \ldots+\ldots- \\
6 \\
16\end{array}$ & $\begin{array}{l}\text { Left eye bandaged. } \\
\text { Martens, optimum. } \\
\text { Do. } \\
\text { Left eye bandaged. }\end{array}$ \\
\hline July 27 & $\begin{array}{l}.18 \\
.19 \\
.13 \\
.18\end{array}$ & $\begin{array}{l}.72 \\
.59 \\
.64 \\
.55\end{array}$ & $\frac{\mathrm{x}}{\mathrm{X}}$ & & $\overline{\mathrm{x}}$ & $\begin{array}{l}17 \text { by } 20- \\
17 \text { by } 20- \\
17 \text { by } 20- \\
17 \text { by } 20 .\end{array}$ & . \\
\hline July 29. & $\begin{array}{l}.49 \\
.31 \\
.23 \\
.33 \\
.20 \\
.19\end{array}$ & $\begin{array}{r}1.36 \\
1.10 \\
.92 \\
1.04 \\
.60 \\
.66\end{array}$ & $\bar{x}$ & & $\begin{array}{c}\mathrm{x} \\
\overline{\mathrm{x}} \\
\overline{\mathrm{x}}\end{array}$ & $\begin{array}{l}4 \\
4 \\
6 \\
6 \\
16 \\
16\end{array}$ & - \\
\hline July 30 & $\begin{array}{l}.50 \\
.56 \\
.36 \\
.50 \\
.22 \\
.20\end{array}$ & $\begin{array}{r}1.70 \\
1.40 \\
1.14 \\
1.08 \\
.67 \\
.68\end{array}$ & \begin{tabular}{c}
$\mathrm{X}$ \\
\hdashline$\overline{\mathrm{X}}$ \\
\hdashline$\overline{\mathrm{X}}$
\end{tabular} & $\frac{-\bar{x}}{\bar{x}}$ & & $\begin{array}{l}4 \\
4 \\
6 \\
6 \\
16 \\
16\end{array}$ & wi \\
\hline August 1 . & $\begin{array}{l}.43 \\
.14 \\
.22 \\
.10\end{array}$ & $\begin{array}{r}1.40 \\
.86 \\
.72 \\
.32\end{array}$ & & & $\begin{array}{l}\mathrm{X} \\
\mathrm{X} \\
\mathrm{X} \\
\mathrm{X}\end{array}$ & 16 & $\begin{array}{l}19 \mathrm{~mm} \text { div. white. } \\
5 \mathrm{~mm} \text { div. white. } \\
1.5 \mathrm{~mm} \text { div. white. } \\
\text { Tissue paper screen. }\end{array}$ \\
\hline August 2 & $\begin{array}{l}.20 \\
.12 \\
.18\end{array}$ & $\begin{array}{l}.40 \\
.50 \\
.48\end{array}$ & & & $\begin{array}{l}\mathrm{X} \\
\mathrm{X} \\
\mathrm{X}\end{array}$ & $\begin{array}{l}17 \text { by } 20 \\
17 \text { by } 20 \\
17 \text { by } 20\end{array}$ & $\begin{array}{l}\text { Do. } \\
\text { Ground glass screen. } \\
\text { Do. }\end{array}$ \\
\hline
\end{tabular}

OBSERVER, IGP

\begin{tabular}{|c|c|c|c|c|c|c|c|}
\hline August 5 & $\begin{array}{r}0.25 \\
.24 \\
.24\end{array}$ & $\begin{array}{r}0.96 \\
.63 \\
.73\end{array}$ & $-\cdots$ & - & $\begin{array}{l}\mathrm{X} \\
\mathrm{X} \\
\mathrm{X}\end{array}$ & $\mid \begin{array}{l}4 \\
6 \\
16 \\
-\end{array}$ & $\begin{array}{l}\text { Ground glass screen. } \\
\text { Do. } \\
\text { Do. }\end{array}$ \\
\hline August 6. & $\begin{array}{l}.25 \\
.20 \\
.82\end{array}$ & $\begin{array}{r}.64 \\
.84 \\
1.23\end{array}$ & & & $\begin{array}{l}\mathrm{X} \\
\mathrm{X} \\
\mathrm{X}\end{array}$ & $\begin{array}{l}16 \\
4 \\
1 \\
1 \\
-\end{array}$ & $\begin{array}{c}\text { Do. } \\
\text { Do. } \\
\text { No screen. }\end{array}$ \\
\hline August 7 & $\begin{array}{l}.28 \\
.25\end{array}$ & $\begin{array}{l}.90 \\
.79\end{array}$ & & & $\underset{\mathrm{X}}{\mathrm{X}}$ & $\begin{array}{l}6 \\
16\end{array}$ & $\begin{array}{l}\text { Ground glass screen. } \\
\text { Do. }\end{array}$ \\
\hline August 8 & $\begin{array}{l}.29 \\
.38\end{array}$ & $\begin{array}{l}.58 \\
.52\end{array}$ & & & $\underset{\mathrm{X}}{\mathrm{X}}$ & $\begin{array}{l}16 \ldots \\
6 \ldots\end{array}$ & $\begin{array}{l}\text { Do. } \\
\text { Do. }\end{array}$ \\
\hline August 9 & $\begin{array}{l}.31 \\
.47\end{array}$ & $\begin{array}{l}.87 \\
.84\end{array}$ & $\underset{\mathrm{X}}{\mathrm{X}}$ & & & $\begin{array}{l}6 \\
6 .-\end{array}$ & $\begin{array}{l}\text { Martens, optimum. } \\
\text { Do. }\end{array}$ \\
\hline
\end{tabular}

In Table 1 may be found a summary of all the results on which this report is based. The remainder of the paper consists of an analysis and discussion of these results. The first column gives the date of observation; the second column gives the $P E_{\text {slngle }}$ in terms of 
volts based on 30 settings (except for the days July 30, August 1 and 2 when only 20 settings, 10 GID and 10 LPD settings, are represented). The third column gives the "just doubtful difference" in terms of volts. The last column serves to specify whether the prism of opal glass was viewed directly (usually no remark) or whether there was a translucent screen placed perpendicular to the line of sight in the plane of the prism edge (tissue paper screen, ground glass screen), whether the Martens photometer was used in the usual way

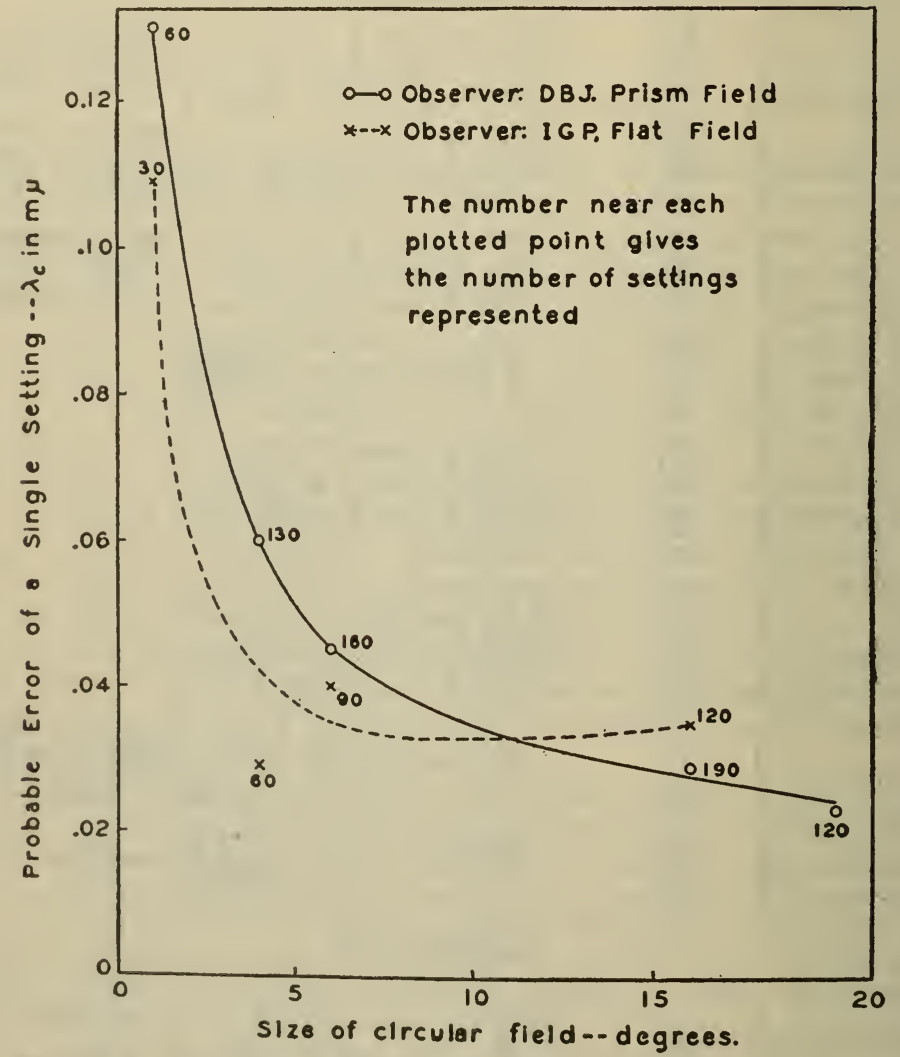

FigURE 1.-Precision as a function of field size indicated on the spectral centroid scale by the probable error of a single observation

(Martens, optimum) or with brightness adjustment by means of the lamp distances rather than by rotation of the circle (Martens, no circle), whether (when the right eye was used alone) the left eye was kept closed by a bandage around the head (left eye bandaged) or was shielded from the observing field by a gray screen fastened over the left spectacle lens (no remark), and whether the dividing line was light gray and $0.5 \mathrm{~mm}$ wide (no remark) or light gray of some indicated width ( $5 \mathrm{~mm}$ div. white) or dark gray of some indicated width ( $5 \mathrm{~mm}$ div. black). 


\section{SENSIBILITY AS A FUNCTION OF FIELD SIZE}

Figure 1 shows the average $P E_{\text {single }}$ plotted for each observer against field size. The largest field was $17^{\circ}$ by $20^{\circ}$ rectangular, and, since the other fields were circular, the values corresponding to this rectangular field were plotted (somewhat arbitrarily) at $20^{\circ}$ because that seemed to be the size of circular field corresponding as far as sensibility is concerned to the $17^{\circ}$ by $20^{\circ}$ rectangular field. Figure 2 shows the average "just doubtful difference" plotted against field size. For observer DBJ, only results for which the prism was viewed directly were considered. About half of these observations were with

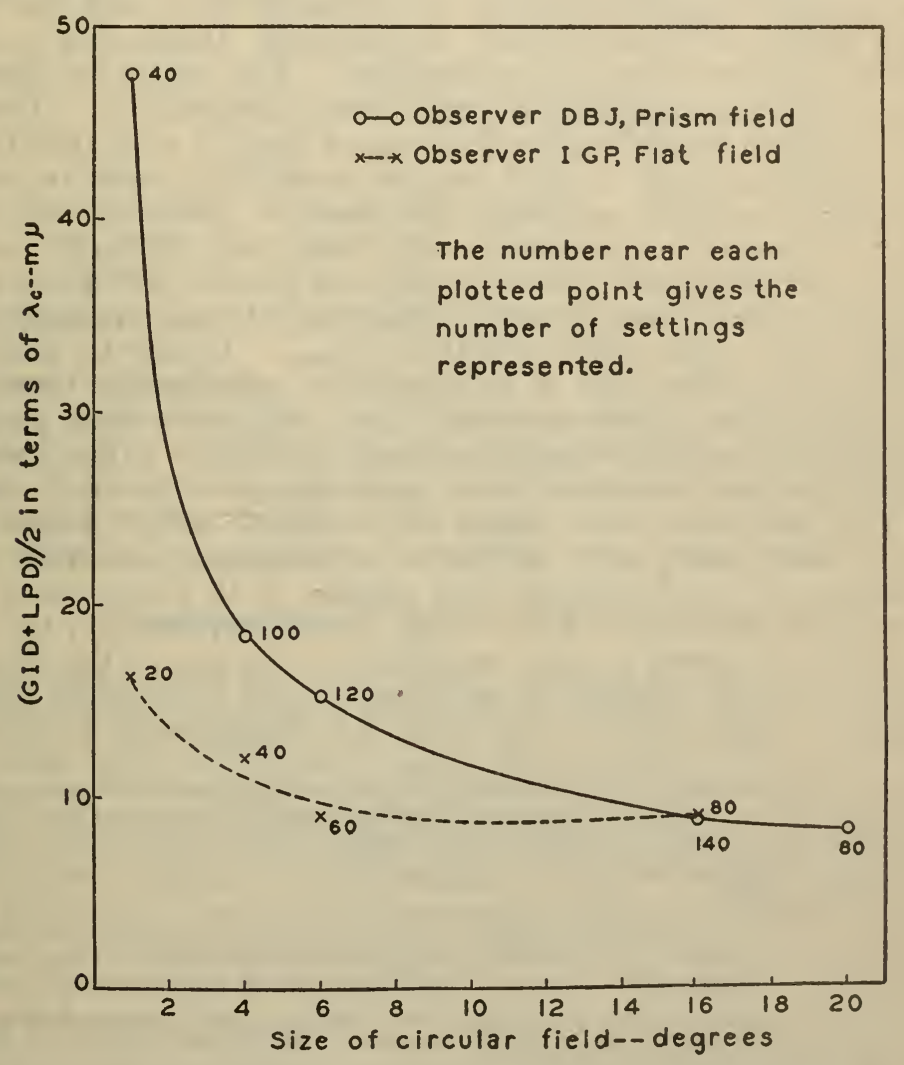

FIGURE 2.-Precision as a function of field size indicated on the spectral centroid scale by the "just doubtful difference"

binocular vision and half with monocular vision as may be seen from Table 1. For observer IGP, the flat field and binocular vision were used in all results considered. The dividing line for all values plotted in Figures 1 and 2 was light gray and about $0.5 \mathrm{~mm}$ wide and subtended about $0.08^{\circ}$ at the average observing distance of $35 \mathrm{~cm}$. As will appear later (Fig. 3 ) the effect of this line on sensibility to colortemperature change is negligible. The values averaged were weighted according to the number of settings represented. The ordinates of Figures 1 and 2 are plotted in terms of the spectral centroid of light 
$\left(\lambda_{c}\right)^{16}$ in $\mathrm{m} \mu$. By calibration of the lamp we used in terms of the spectral centroid of light it was found that at 79 volts, 1 volt corresponded to a change in $\lambda_{c}$ of $0.133 \mathrm{~m} \mu$; the results summarized in Table 1 were multiplied by this factor in order to express them on the $\lambda_{c}$ scale.

The function of probable error against field size might be expected to approximate a hyperbola; that is, the probable error must, of necessity, rise to infinity for zero field size, and, unless stimulation of the periphery actually interferes with the use of the more central regions of the retina (which seems scarcely probable), the probable error should approach more and more nearly its lowest value as the field size approaches that of the visual field itself. Examination of Figures 1 and 2 shows that both the probable error and the "just doubtful difference" (particularly for observer DBJ) give a curve with field size that is roughly hyperbolic. ${ }^{17}$ The points for observer IGP do not follow any regular curve very satisfactorily. There is a decided gain in sensibility for field sizes $4^{\circ}$ and $6^{\circ}$ over that for $1^{\circ}$, but for further increase in field size the sensibility seems to remain substantially constant, although the observer preferred the large fields and thought his precision with them was distinctly better.

Table 2 evaluates from the data which are plotted on Figures 1 and 2 the ratio of the "just doubtful difference" to the probable error of a single observation (GID + LPD) $/ 2 P E_{\text {single. }}$ It may be seen that the approach to constancy of this ratio is considerably better for observer DBJ than for observer IGP, but this is at least partially due to the larger number of settings made by DBJ. (Figs. 1 and 2.) This ratio has been evaluated from more extensive data (six observers on the dominant wave length of Lovibond $35 \mathrm{Y})^{18}$ which gave 3.56; and from much more extensive unpublished data (the same six observers on the dominant wave lengths of 45 filters, more than 8,000 settings) which gave 3.21 . This ratio is expected on the basis of the theory of error's to vary according to the size of the stimulus increments and the number of scrutinfies of the field which precede a judgment. The value of the ratio, 3.3, corresponds to average

10 The spectral centroid of light, being a general parameter, is naturally of more interest than scale vol tage of our particular lamp. It possesses a unique importance here because of the discovery by Priest ('The Colori metry and Photometry of Daylight and Incandescent Illuminants by the Method of Rotatory Dispersion. J. Opt. Soc. $\Lambda \mathrm{m}$. and Rev. Sci. Iust., $\gamma$, pp. 1190-1191; 1923) that the observational precision of measurement of $\lambda_{c}$ is epproximately constant indepcndent of color temperature. It is of interest to quote a few paragraphs from Priest's paper.

"To state this somewhat more concretely, the probable error of $\lambda_{c}$ as computed from the observad residuals ${ }^{*}{ }^{*}$ in any set of observations, is constant; that is, independent of the particular value of $\lambda_{c}$ (or color temperature) being measured. This statement is based on a very large amount of onservational data which can not be reproduced here; but these data warrant the statement with the follow. ing qualifications:

“(I) That the range of color tempcrature actually covered by the expcrimental data lies between about $3,000^{\circ}$ and $20,000^{\circ} \mathrm{K}$. (The author is of the opinion that substantially the same probable error would be found for tempcratures between $2,000^{\circ}$ and $3,000^{\circ}$.)"

Subsequent tests have amply borne out this opinion. When expressed in terms of spectral centroid of light, then, our conclusions may be taken to apply to a wide range of black-body colors instead of mercly to the restricted neighborhood of $2,700^{\circ}$ at which the obscrvations wcre taken. We continue to quote from Priest's paper:

"(2) By constancy in this case is meant that the probable error of a single observation lies, in general, betwern 0.1 and 0.2 millimicrons without showing any indication of systematic variation with temperature. These values apply only to certain experimental conditions. Absolutely smaller probable errors can probubly be obtained uncler improved conditions of observation."

Figure 5 shows to what a gratifying extent this prediction has been rcalized. Under optimum conditions, the lew alparatus has permittcd observations having a probable crror for a single setting of but $0.02 \mathrm{~m} u$. These observations are almost of a dillerent order of precision; the probable errors are less than one-fifth thuse reported in I'riest's 1923 paper.

17 'The similarity of the curves on Figures 1 and 2 is, as has already been pointed out, to be expected. In fact, as will appear presently (Table 2), the probable error of a single observation and the "just doubtful difference" are for observer 1DBJ very nearly proportional.

11 I. ( . Priest and D. B. Judd, Sensibility to Wave-Length Difference and the Precision of Measurement of Dominant Wave Length for Yellow Colors of High Saturation, J. Opt. Soc. Am. and Rev. Sci. Inst., 14,
p. 137; 1927. 
observing technique and between 2 and 3 scrutinies. We make use of this proportionality in reducing the none too numerous data of the next subsection.

TABLE 2.-The "just doubtful difference" compared to the probable error of a single observation

\begin{tabular}{|c|c|c|c|c|}
\hline Observer & $\begin{array}{c}\text { Field } \\
\text { size, } \\
\text { degrees }\end{array}$ & 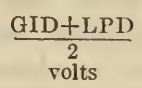 & $\underset{\text { volts }}{P E_{\text {, inglo }}}$ & $\frac{G I D+L P D}{2 P E_{\text {singlo }}}$ \\
\hline DBJ.-. & $\begin{array}{r}1 \\
4 \\
6 \\
16 \\
17 \text { by } 20\end{array}$ & $\begin{array}{r}3.57 \\
1.38 \\
1.14 \\
.67 \\
.62\end{array}$ & $\begin{array}{l}0.98 \\
.45 \\
.34 \\
.22 \\
.17\end{array}$ & $\begin{array}{l}3.64 \\
3.07 \\
3.35 \\
3.05 \\
3.65\end{array}$ \\
\hline Mean.- & 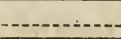 & - & - & 3.35 \\
\hline IGP... & $\begin{array}{r}1 \\
4 \\
6 \\
16\end{array}$ & $\begin{array}{r}1.23 \\
.90 \\
.68 \\
.68\end{array}$ & $\begin{array}{l}.82 \\
.22 \\
.30 \\
.26\end{array}$ & $\begin{array}{l}1.50 \\
4.09 \\
2.27 \\
2.62\end{array}$ \\
\hline Mean. & & & & 2.62 \\
\hline
\end{tabular}

\section{SENSIBILITY AS A FUNCTION OF WIDTH OF THE DIVIDING LINE}

Figure 3 shows that sensibility falls off rapidly with increasing width of a dividing line which contrasts sharply with the field. If the contrast is not sharp the loss in sensibility is considerably less rapid. It is seen that no loss in sensibility need be ascribed to the $0.5 \mathrm{~mm}$ light gray dividing line which was present throughout the whole series of observation even with the $1^{\circ}(7 \mathrm{~mm})$ field..$^{19}$

\section{IMPORTANCE OF THE SUBSTITUTION METHOD}

Since nothing has been said of the means about which the residuals for the probable errors have been taken it might, perhaps, be assumed that these mean values showed only such variation among themselves (lamp No. 2 illuminating the right field was always kept at a voltage of 80.0) as would be expected from their probable errors, but such is far from the case. Although the means taken under identical experimental conditions agreed excellently well, a change (for example) from observation of the $17^{\circ}$ by $20^{\circ}$ field with both eyes to observation of the same field with the right eye brought a difference of 1 volt between the two means of 60 settings each. Since the probable error of the difference was found to be but 0.04 volts, it is plain that this difference is not ascribable to random variations; in fact, it will occur on a purely chance basis only about once in $10^{44}$. An analysis of all the data taken before July 30 showed some definite regularities that are illustrated in Figure 4.

It is seen that the use of the right eye never required the lamp illuminating the left half of the field to be operated at as high a voltage for a color match as the use of both eyes. Furthermore, this difference in voltage increases for smaller field sizes in a regular fashion. ${ }^{20}$

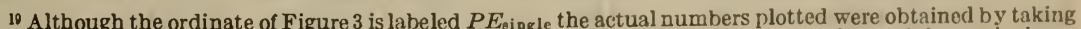
the average of the $P E$ single and $1 / 3.3$ times the "just doubtful difference." By virtue of the equivalence of these two quantities (Table 2) for observer DBJ, the resulting average was labeled $P E_{\text {sinale; it mighc }}$ with equal applicability have been labeled 1/3.3 times the "just doubtful difference."

20 Since this difference is found to be roughly proportional for all field sizes to the probable error of a siuglu observation, it is just as significant (though of smaller absolute value) for the $20^{\circ}$ field as for the $4^{\circ}$. 
It is also true (though less precisely established) that use of the left eye requires an even higher applied voltage for the lamp illuminating the left half of the field than both eyes. ${ }^{21}$ The curve for both eyes falls (except for one not too well-determined point) between that for the left and that for the right eye, being, however, distinctly closer to that for the left eye. This circumstance leads immediately to the conclusion that when both eyes are being used the left eye is the dominant one. Such a conclusion seems strange because the author habitually uses his right eye in close observation so much that he finds some difficulty in fixating with his left eye alone; perhaps, the

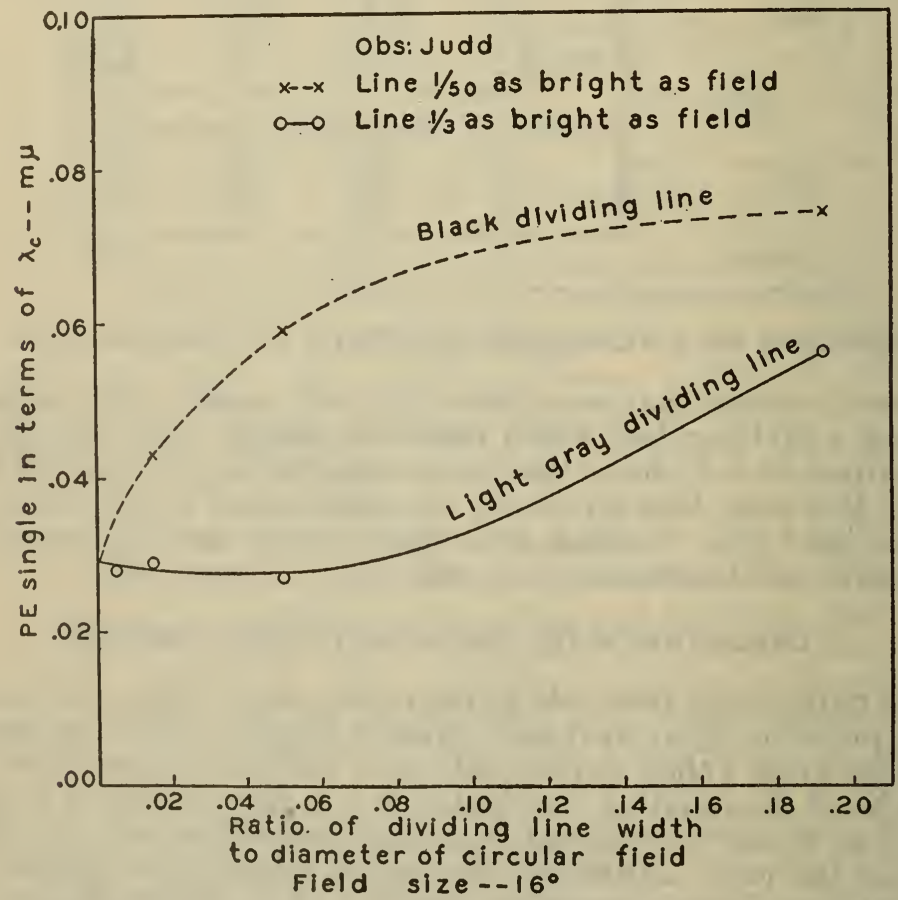

FIGURE 3.- Probable error of a single observation as a function of width of dividngi line relative to diameter of the field

Note that a black dividing line although quite narrow reduces precision considerably, but a line of small contrast may be as wide as one-tenth the diameter of the field without causing much loss in precision.

explanation is to be found in the fact that many of the observations which go to determine the curve for both eyes (Table 1, July 27 and 29) were made with the right eye fatigued by previous observation.

Whatever the ultimate explanation of these results, apparently we must conclude the immediate cause to be that the nasal halves of the author's foveal and parafoveal retinal regions were yellow sensitive compared to the temporal halves. The argument is as follows: In the first place we speak of the retinal region near the optic axis of the eye rather than of that of the whole eye because the discrepancy

"These remarks refer to observer DBJ alone because (Table 1) observer IGP did not employ monocular
observation at all with tho new apparatus. 
between the eyes decreases as more and more of the outlying retinal regions come into function. The fact that the use of the region near the left fovea required a high applied voltage on lamp No. 1 for a color match leads to the conclusion that the half of the retina of the left eye illuminated by that lamp must have been yellow sensitive compared to the other half. But lamp No. 1 illuminated the left half

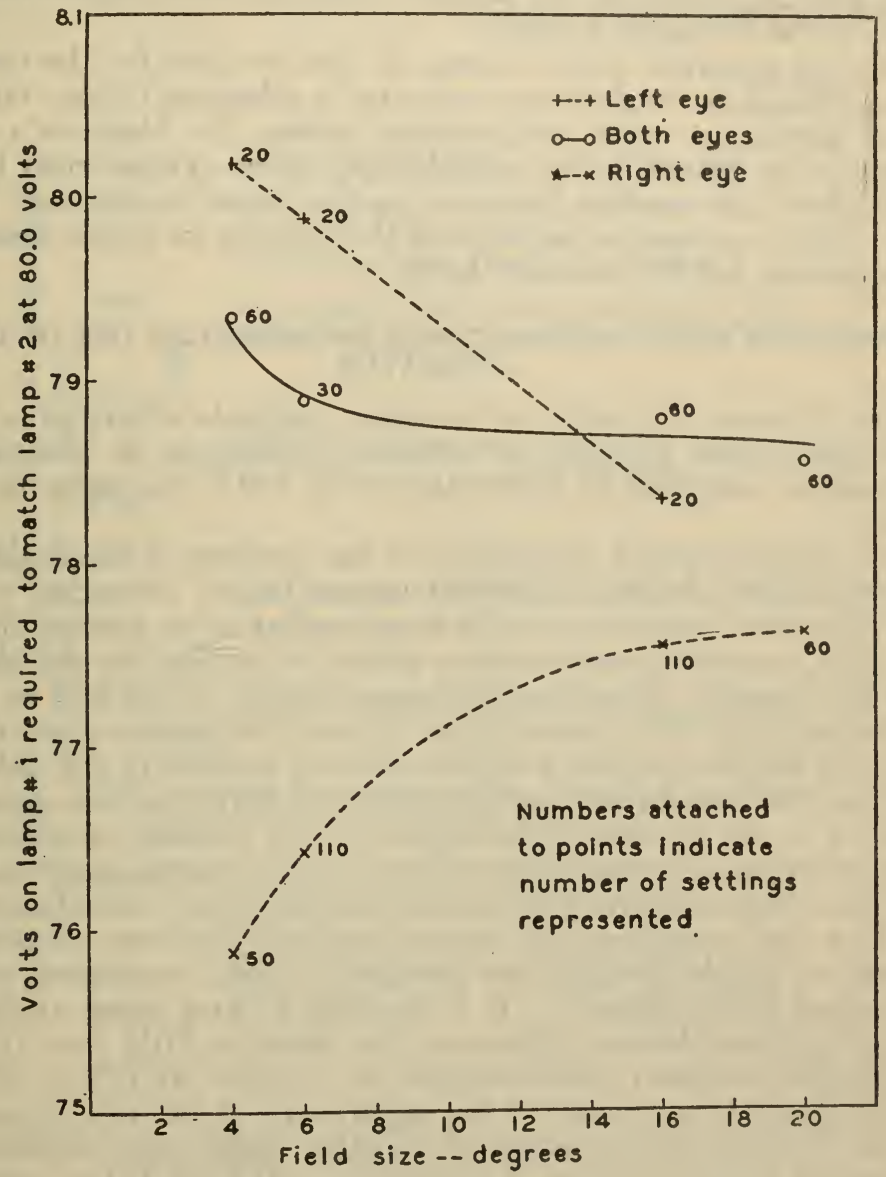

Figure 4.-An illustration of the variation in voltage required to produce a color match which is to be ascribed to asymmetry of retinal sensitivity about the vertical median line

The importance of using a strict substitution method in comparing lamps as to color temperature is emphasized.

of the field which, in turn was imaged mostly ${ }^{22}$ on the nasal half of the central retina of the left eye. Hence, the nasal half of the central retina of the left eye must have been relatively yellow sensitive. Since the use of the right eye required a low applied voltage, the half of the central retina of the right eye affected by lamp No. 1 must have been blue-sensitive. But lamp No. 1, illuminating the left half

${ }^{22}$ Entirely except for excursions of the fixation point from the dividing line. 
of the field, affected the temporal half of the central retina of the right eye. Hence, the temporal half of the central retina of the right eye must have been blue sensitive relative to the other half. But this is just another way of saying that the nasal half of the central retina of the right eye was relatively yellow sensitive. A short way of stating both conclusions is to say that the nasal halves of the central portions of both the author's retinae were yellow sensitive relative to the temporal halves. ${ }^{23}$

It is quite apparent that a change in the eye used for the observation or a change in the field size is not to be tolerated in the standardizing of lamps for color temperature unless the observer's visual mechanism be proven to be considerably more symmetrical in sensitivity about the median line than is the visual mechanism of the author. In the absence of such proof the lamp to be tested must be a true substitute for the standard lamp.

\section{COMPARISON WITH THE PRECISION OBTAINED BY USE OF OTHER APPARATUS}

Figure 5 shows a number of average probable errors of a single observation on the $\lambda_{c}$ scale for different conditions of observation; the left scale referring to observations by $\mathrm{DBJ}$, the right to those by IGP.

It may be first noted (beginning at the bottom of the scale) that the introduction of the translucent screen before the prism of opal glass in the new apparatus results in somewhat more precise observation. This increased precision may either be ascribed to the elimination of the possibly disturbing tridimensionality of the field or to the fact that the flat field (tissue-paper screen, or ground-glass screen) exhibited a definite texture which facilitated fixation of the field.

Next may be noted that (for both DBJ and IGP) the new apparatus is superior to the Martens photometer for the purpose of standardizing lamps for color temperature. This result is particularly interesting because the Martens photometer has tbeen very satisfactory for other uses and possesses not only a perfectly uniform photometric field with no visible dividing line but also a highly convenient method of adjusting the brightness. It is possible to give some analysis of the superiority of the new apparatus for observer DBJ thus (1) from Figure 1 the increased field size from $6^{\circ}$ circular to $17^{\circ}$ by $20^{\circ}$ rectangular accounts for much of the superiority of the new apparatus, (2) from Figure 3 the presence of a visible, light gray, dividing line with the new apparatus is no disadvantage, (3) from Table 1 (July 27) the use of both eyes is no advantage with the prism field, and can not be much advantage with the flat field (August 1 and 2 ) because the decrease in probable error due to the introduction of the translucent screen with binocular vision is not great $(0.23$ to $0.20 \mathrm{~m} \mu$, fics. 5) and is ascribable to two other factors (see above), (4) but from Figure 5 (compare 0.59 with $0.35 \mathrm{~m} \mu$ ) the brightness adjustment by the now apparatus is distinctly inferior to that of the Martens photometer, and (5) either the necessity of keeping the eye at the

Note that wo know nothing concerning the relative yellow-blue sensitivity of the portions of the retina farthest from the fovea which were functional in the experiment because we can not pay that the decrease in the difference in applied voltage with increased fleld size is actually due to partial compensation of the rentral inequalities (though that is strongly suggested). The decrease in the difference between the two iug far from the dividing line fact that with a larger field there is more chance of the fixation point wander- 
artificial pupil or the dark surrounding field of the Martens photometer is a considerable disadvantage because (fig. 5) the Martens photometer without its particularly convenient brightness adjustment yielded an average probable error higher $(0.59 \mathrm{~m} \mu)$ than the new apparatus for the same field size. (Fig. 1 for $6^{\circ}, 0.45 \mathrm{m \mu}$.) For this observer ${ }^{24}$ the advantages of the new apparatus may, therefore, be summarized as (1) large field, and (2) use of the natural pupil with light surroundings. These two advantages more than outweigh the

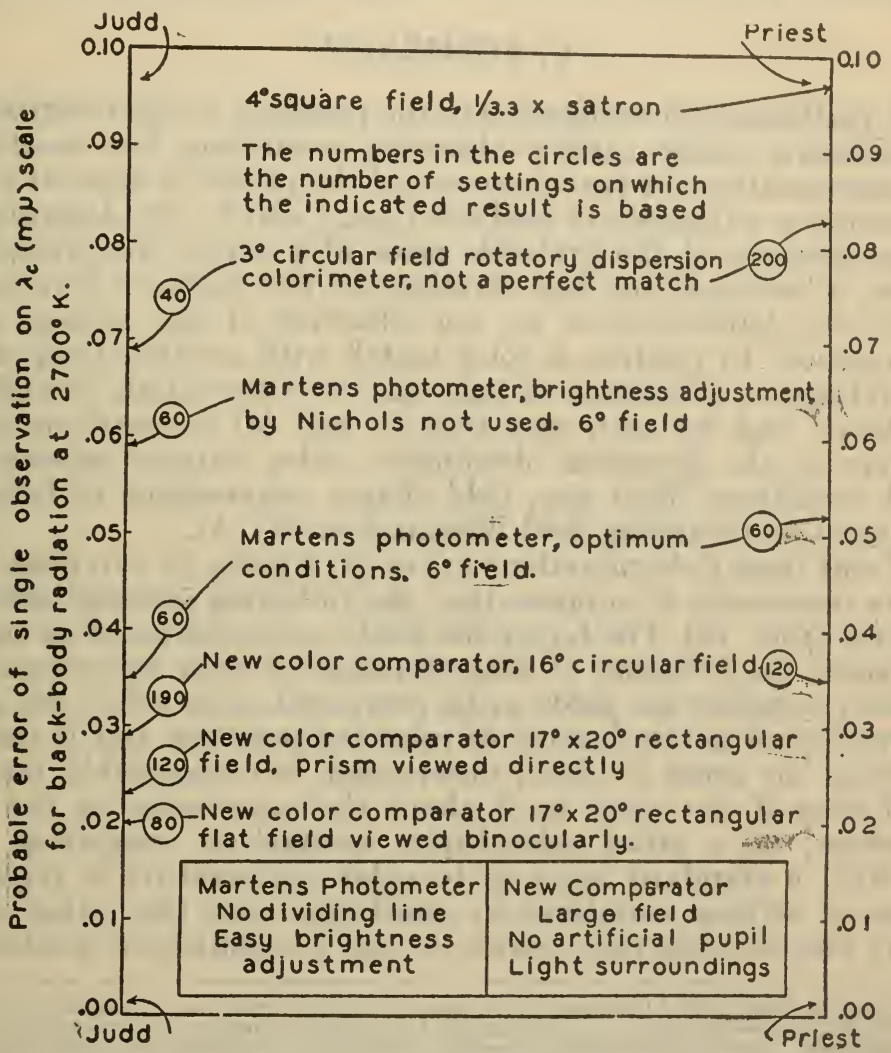

FIGURE 5.-Comparison of the precision attained by using the nevo color comparator with that attained by other apparatus

The characteristics of the Martens photometer which are responsible for its high precision are also summarized in contrast with those of the new comparator.

superior method of brightness adjustment of the Martens photometer. The advantage of using both eyes with the new apparatus and the disadvantage of the light gray dividing line are alike without appreciable effect on precision for restricted periods of observation. However, there seems to be a distinct gain in comfort and relaxation due to the use of both eyes with the flat field. It seems probable that an observer might find a significant gain in precision for extended periods

24 Although the observations of IGP are not sufficiently extensive to form the basis for a similar analysis, it is probable that the conclusions would be similar except that the advantage of increasing the field size would not be so great. (Fig. 1.) 
of observation due to the avoidance of fatigue, but this gain has not yet been experimentally realized.

The superiority of the new apparatus over either the $3^{\circ}$ circular field of the rotatory dispersion colorimeter or the $4^{\circ}$ square field of Priest's monochromatic colorimeter is quite marked, since it yields probable errors that are between one-half and one-third those previously obtained. (Fig. 5.) ${ }^{25}$ The design of the new color comparator has, therefore, been justified in a most gratifying way. ${ }^{26}$

\section{SUMMARY}

1. A preliminary investigation of the precision of color-temperature measurements under various observing conditions has resulted in: (a) Determination for two observers of the probable error of a single observation as a function of field size (figs. 1 and 2 ); (b) determination for one observer of the probable error of a single observation as a function of width of the line dividing the two fields to be compared (fig. 3); (c) determination for one observer of the voltage of one lamp required to produce a color match with another lamp at constant voltage as a function of field size for observation by right eye, by left eye, and by both eyes (fig. 4 ), and $(d)$ comparison for two observers of the precision obtainable under various miscellaneous special conditions (field size, field shape, convenience of brightness adjustment, surrounding field illumination, fig. 5).

2 . From these determinations $(a)$ to $(d)$ by one or two observers it appears reasonable to suppose that the following generalizations $(a)$ to $(d)$ are true: $(a)$ The larger the fields to be compared as to color, the greater the precision of determination of color temperature; $(b)$ the closer together the fields to be compared as to color, the greater the precision of determination of color temperature, but if the space separating the areas is black, observation is considerably more disturbed than if the space is of about the same color as the areas, themselves; $(c)$ a strict substitution method in comparing a test lamp with a standard lamp as to color temperature is imperative because of serious variations in sensibility over the retina of supposedly normal observers; failure to use a substitution method may

${ }^{28}$ The value for observer DBJ $(0.069 \mathrm{~m} \mu)$ on the rotatory dispersion colorimeter was inferred from a group of 140 settings made for the purpose of calibrating the lamps used throughout the experiments in terms of color temperature. None of the 140 settings were made at the applied voltage to which the other probable errors refer, but the inferred value was estimated to have the weight of about 40 settings. There was a troublesome red-green difference between the two halves of the field for high applied voltages $\left(2,848^{\circ} \mathbf{K}\right.$.) which became less as the voltage decreased. The value for observer IGP $(0.083 \mathrm{~m} \mu)$ was obtained from previous unpublished work, as was also the value for the "satron" in terms of spectral centroid. The term, "satron," was proposed by Priest in 1927 who defined it as follows: "For colors of low saturation, one satron is the increment in saturation due to an increment in purity equal to $P^{\prime}$ o where $P^{\prime}$ o, a function of dominant wave length, is taken as $\left(P_{\max }+P_{\min }\right) / 2$ from the mean values of Priest and Brickwedde." since in the notation developed in this paper $\left(P_{\max }+P_{\min }\right) / 2$ would be written $\left(P\right.$ LPD $\left.+P_{\mathrm{gID}}\right) / 2$, it is apparent that the "satron" is a "just doubtful difference" in saturation for unsaturated colors observed under the conditions used by Priest and Brickwedde, see footnote 12, p. 1165. The probable error of a single observation corresponding to observations of such precision that the "satron" constitutes the "just doubtful difference" was obtained by dividing the value for the "satron" on the spectral-centroid scale by 3.3 . (Table 2.) The fact that this probable error $(0.097 \mathrm{~m} \mu)$ which refers to the $4^{\circ}$ square field of Priest's monochromatic colorimeter is somewhat greater than the value $(0.083 \mathrm{~m} \mu)$ obtained by the same observer $\left(\mathrm{IO} \mathrm{P}^{\prime}\right)$ for the smaller fleld ( $3^{\circ}$ circular) of the rotatory dispersion colorimeter may occasion some surprise; but it may well be due to the superior brightness-adjustment device incorporated in the rotatory dispersion colorimeter.

${ }^{36}$ Since no data referring to observer DBJ or observer IGP are available for the Lummer-Brodhun contrast photometer, a direct comparison with the precision obtainable by this instrument is not possible. According to Forsythe (W. E. Forsythe, Accuracy in Color Matching of Incandescent Light Sources, J. Opt. Soc. Am. and Rev. Scl. Inst., 6, pp. 476-482; 1922) this precision is quite high. The average mean variation in 835 settings distributed among seven observers indicates the probable error of a single setting to be about the same as the lowest value $(0.02 \mathrm{m \mu})$ obtained on the new color comparator. The advantage of the contrast fleid is emphasized by Forsythe, but the results reported here would suggest that the large fleld $\left(10^{\circ}\right.$ or $\left.15^{\circ}\right)$ might be the important factor. 
cause errors in special cases of more than 25 times the probable error of a single observation; and $(d)$ the new color comparator which was constructed during the course of these preliminary measurements permits the visual determination of color temperature with a precision two or three times as great as the instruments previously used for this purpose at the National Bureau of Standards (Martens photometer, rotatory dispersion colorimeter).

Washington, September, 1930. 